Artigo

\title{
Albedo do Solo abaixo do Dossel em Área de Vochysia divergens Pohl no Norte do Pantanal
}

\author{
Jonathan Willian Zangeski Novais ${ }^{1}$, Luciana Sanches ${ }^{2}$, Ludymilla Barbosa da Silva ${ }^{3}$, \\ Nadja Gomes Machado ${ }^{4}$, Aryadne Márcia Aquino ${ }^{5}$, Osvaldo Borges Pinto Junior ${ }^{1}$ \\ ${ }^{1}$ Programa de Pós-Graduação em Ciências Ambientais, Universidade de Cuiabá, \\ Cuiabá, MT, Brasil. \\ ${ }^{2}$ Departamento de Engenharia Sanitária e Ambiental, Universidade Federal de Mato Grosso, \\ Cuiabá, MT, Brasil. \\ ${ }^{3}$ Departamento de Ciências Biológicas, Universidade do Estado de Mato Grosso, \\ Tangará da Serra, MT, Brasil. \\ ${ }^{4}$ Laboratório de Biologia da Conservação, Instituto Federal de Mato Grosso, \\ Cuiabá, MT, Brasil. \\ ${ }^{5}$ Programa de Pós-Graduação em Física Ambiental, Universidade Federal de Mato Grosso, \\ Cuiabá, MT, Brasil.
}

Recebido: 4/1/2015 - Aceito: 15/6/2015

\begin{abstract}
Resumo
Este artigo analisou o albedo do solo $\left(\alpha_{\text {solo }}\right)$ abaixo do dossel considerando duas etapas no ciclo hidrológico, a primeira em que o solo estava inundado e a segunda em que o solo estava coberto por serrapilheira acumulada sobre o solo em área inundável de Vochysia divergens Pohl no Pantanal, Brasil. Os valores de $\alpha_{\text {solo }}$ foram calculados pela relação entre as radiação solar global refletida e a incidente medidas abaixo do dossel por meio de estações meteorológicas. A inundação da área ocorreu durante fevereiro a junho e posteriormente houve um aumento gradativo de serrapilheira acumulada sobre o solo. $\mathrm{O} \alpha_{\text {solo }}$ variou sazonalmente com maiores valores durante o período seco em que houve um aumento de aproximadamente $42 \%$ do $\alpha_{\text {solo }}$ em relação ao período com inundação. Análises de correlação cruzada entre o $\alpha_{\text {solo }} \mathrm{e}$ precipitação, umidade do solo e a serrapilheira acumulada sobre o solo explicam em parte a influência direta e/ou indireta sobre o $\alpha_{\text {solo }}$. A precipitação não influenciou diretamente sobre o $\alpha_{\text {solo }}$ do mês atual, enquanto que a umidade do solo influenciou diretamente sobre o $\alpha_{\text {solo }}$ no mês atual e nos seguintes meses, e a serrapilheira acumulada do solo correlacionou-se positivamente com o $\alpha_{\text {solo }}$ indicando influência direta no mês atual.
\end{abstract}

Palavras-chave: cambarazal, serrapilheira acumulada sobre o solo, umidade do solo, refletância do solo.

\section{Soil Albedo below the Canopy in Area of Vochysia divergens Pohl in the North of the Pantanal}

\begin{abstract}
This paper analyzed the soil albedo $\left(\alpha_{\text {soil }}\right)$ below the canopy considering two steps in the hydrological cycle, the first when the soil was flooded and the second when the soil was covered with litterpool in a flooded area of Vochysia divergens Pohl in the Pantanal, Brazil. The values of $\alpha_{\text {soil }}$ were calculated by the ratio between the reflected solar radiation and incident solar radiation measured below the canopy through weather stations. The flooding occurred during February-June with posterior gradual increase in the litterpool. The $\alpha_{\text {soil }}$ varied seasonally with higher values increasing approximately $42 \%$ of the soil albedo during the dry period compared to the inundation period. Cross-correlation analysis between $\alpha_{\text {soil }}$ and accumulated rainfall, soil moisture and litterpool may partly explain the direct and/or indirect influence on the $\alpha_{\text {soil }}$. The rainfall did not influence directly on the $\alpha_{\text {soil }}$ of the current month, while the soil moisture influenced directly on the $\alpha_{\text {soil }}$ in the current month and the following months, the litterpool and $\alpha_{\text {soil }}$ were positively correlated in the current month indicating direct influence on the $\alpha_{\text {soil }}$.
\end{abstract}

Keywords: cambarazal, litterpool, moisture soil, soil reflectance.

Autor de correspondência: Luciana Sanches, e-mail: 1sanches@hotmail.com. 


\section{Introdução}

O Pantanal é a maior planície de inundação do mundo com uma área de aproximadamente $150.000 \mathrm{~km}^{2}$ (Gonçalves et al., 2011) e um dos ecossistemas com maior complexidade hidrológica de zonas alagadas (Da Silva, 2000; Da Silva e Girard, 2004; Junk et al., 2006; FantinCruz et al., 2008). O Pantanal faz parte da Bacia Hidrográfica do Alto Paraguai, estendendo por todo oeste do Brasil e partes da Bolívia e do Paraguai, composto por uma gama gramíneas, planaltos de savana (Victoria et al., 1995) e florestas (Zeihofer et al., 2001).

Uma das características hidrológicas do Pantanal é que no período de cheia, há um fluxo de águas das regiões mais elevadas do cerrado para as mais baixas, favorecendo o acúmulo de água aprisionado nas baixas áreas, devido à baixa declividade do local, de 2 a $3 \mathrm{~cm} \mathrm{~km}^{-1}$ de norte a sul e de 5 a $25 \mathrm{~cm} \mathrm{~km}^{-1}$ de oeste para leste. Assim, na maior parte do Pantanal, a inundação dá-se por transbordamento de rios, onde a inundação por precipitação ocorre independentemente das inundações fluviais (Iriondo, 2004; Zeilhofer e Schessl, 2001; Zeilhofer e Moura, 2009).

Essa dinâmica sazonal da inundação afeta os processos hidrológicos, como evaporação nas áreas alagadas, podendo ser consideradas duas etapas: uma primeira etapa, em que se dá a inundação durante a estação chuvosa e uma segunda etapa, durante a estação seca (Schwerdtfeger et al., 2014), e consequentemente há influencia sobre os processos ecofisiológicos e energéticos do ecossistema.

Por outro lado, os processos ecofisiológicos e energéticos, hidrológico e de carbono de um ecossistema também são regulados pela troca de gases que são afetados diretamente pelo albedo (Wang et al., 2002) porque determina diretamente a quantidade de energia solar absorvida pelo solo (Novais et al., 2013) e, por conseguinte, a quantidade de energia disponível para o aquecimento do solo e inferior atmosfera e evaporar a água.

$\mathrm{O}$ albedo de uma superfície quantifica a fração de entrada da radiação solar global que é refletida pela superfície retornando para a atmosfera. $\mathrm{O}$ albedo em áreas alagadas pode ser particularmente difícil de quantificar devido dinâmica de inundação, considerando ainda a variação temporal e espacial da inundação nestas áreas (Sumner et al., 2011). A média diária do albedo da água é menor do que a maioria dos outros sistemas naturais (Brutsaert, 1982) e, consequentemente em áreas alagadas existe um contraste nas propriedades reflexivas do solo durante o período de inundação e o seco (Sumner et al., 2011).

Em modelos climáticos e hidrológicos, por exemplo, um dos grandes desafios é estabelecer as incertezas na quantificação do albedo (Twine et al., 2004). Nestes modelos, para a simulação do albedo superficial é considerada a divisão do albedo da superfície em componentes do albedo do solo e da vegetação porque os processos são diferentes em função da escala de tempo. $O$ albedo da vegetação varia principalmente junto com a estação de crescimento, en- quanto o albedo do solo está associado às variações hidrológicas, como por exemplo, variações diárias causadas por eventos de chuva (Liu et al., 2014). Assim, o conhecimento das mudanças de albedo no espaço e no tempo é crucial para entender o balanço global de radiação e sua influência no clima e dinâmica da vegetação (Lucht et al., 2000).

Neste sentido, a disponibilidade de dados de séries temporais medidos, sincronizados com medições em campo, podem contribuir para o entendimento em escala espacial e temporal dos ciclos abióticos, biológicos (Loiselle et al., 2001), hidrológicos e climáticos de um ecossistema.

O objetivo deste trabalho foi analisar o albedo do solo $\left(\alpha_{\text {solo }}\right)$ representado pela refletância da radiação solar global abaixo do dossel do solo em área inundável de Vochysia divergens Pohl em 2012.

\section{Material e Métodos}

\subsection{Localização e descrição da área em estudo}

Este estudo foi desenvolvido em uma área situada dentro da Reserva Particular do Patrimônio Natural (RPPN) do Serviço Social do Comércio (SESC) localizada entre as latitudes $16^{\circ} 20^{\prime} \mathrm{S}$ e $16^{\circ} 30^{\prime} \mathrm{S}$ e longitudes $56^{\circ} 25^{\prime} 25^{\prime \prime} \mathrm{O}$ e $56^{\circ} 25^{\prime} 39^{\prime \prime} \mathrm{O}$, aproximadamente $160 \mathrm{~km}$ de Cuiabá - Mato Grosso no Norte do Pantanal.

O clima regional é do tipo Aw segundo a classificação climática de Köppen, caracterizado por ser quente e úmido com chuvas no verão e estiagem no inverno com estações úmida e seca distintas. A precipitação pluviométrica oscila entre 800 e $1500 \mathrm{~mm}^{\text {ano }}{ }^{-1}$ (Johnson et al., 2013; Fantim-Cruz et al., 2010) ocorrendo principalmente entre novembro a abril, meses úmidos. As precipitações de alta intensidade provocam inundações em toda a planície de inundação de baixo-relevo, começando entre novembro a dezembro ou na parte norte do Pantanal. Durante os meses de seca (maio a outubro) a inundação diminui continuamente (Schwerdtfeger et al., 2014).

A topografia da planície de inundação é praticamente plana, levando a inundações durante a estação chuvosa (Fantim-Cruz et al., 2010). Os solos são de origem sedimentar, ocorrendo em fases argilosa e arenosa de forma alternada e descontínua, com a dominância de solos hidromórficos compondo 92,5\% do total (Amaral Filho, 1984).

\subsection{Descrição dos transectos}

Dentro da área em estudo foram delimitados e georreferenciados cinco transectos (denominados A, B, C, D e E) com $50 \mathrm{~m}$ de comprimento e $80 \mathrm{~m}$ de distância entre si, contendo 11 pontos cada um, totalizando 55 demarcações (Fig. 1). Esta área apresenta uma superfície inclinada no sentido SE/NO, com um aumento na inclinação de aproximadamente de $1 \mathrm{~cm} / 12 \mathrm{~m}$ do transecto A para o E, correspondendo a $26 \mathrm{~cm}$ de variação topográfica. 
A vegetação local apresenta predominância de Vochysia divergens Pohl (Vochysiaceae), seguida por Licania parvifolia, Mouriri elliptica e Alchornea discolor. A dominância de $V$. divergens diminui do transecto A para o transecto E. Análises de textura do solo nos transectos descrevem um solo com $\mathrm{pH}$ ácido variando de 5,6 no transecto A a 5,8 nos demais transectos. O solo no transecto A é um solo franco-argiloso e nos demais transectos argiloso segundo análises da textura do solo em amostras coletadas a $0-10 \mathrm{~cm}$ de profundidade do solo com um trado nos 55 pontos em dezembro de 2011 e julho de 2012, totalizando 110 amostras. A granulometria das amostras do solo foi realizada por meio da análise granulométrica.

\subsection{Instrumentação meteorológica}

Um sensor meteorológico (modelo WXT520, Vaisala Inc., Helsinki, Finland) foi instalado a $2 \mathrm{~m}$ de altura do solo. Esse sensor realizou medidas numa frequência de $10 \mathrm{~Hz}$ das seguintes variáveis: radiação solar global $(\mathrm{Rg})$, temperatura do $\operatorname{ar}\left({ }^{\circ} \mathrm{C}\right)$, umidade relativa $(\%)$, pressão do $\operatorname{ar}(\mathrm{hPa})$ e precipitação acumulada média diária $(\mathrm{mm})$. Os dados foram armazenados em um datalogger (modelo CR1000, Campbell Scientific, Logan, Utah, USA), em intervalos de 30 min a aproximadamente $2 \mathrm{~km}$ de distância da área em estudo durante o ano de 2012. Esta estação estava instalada
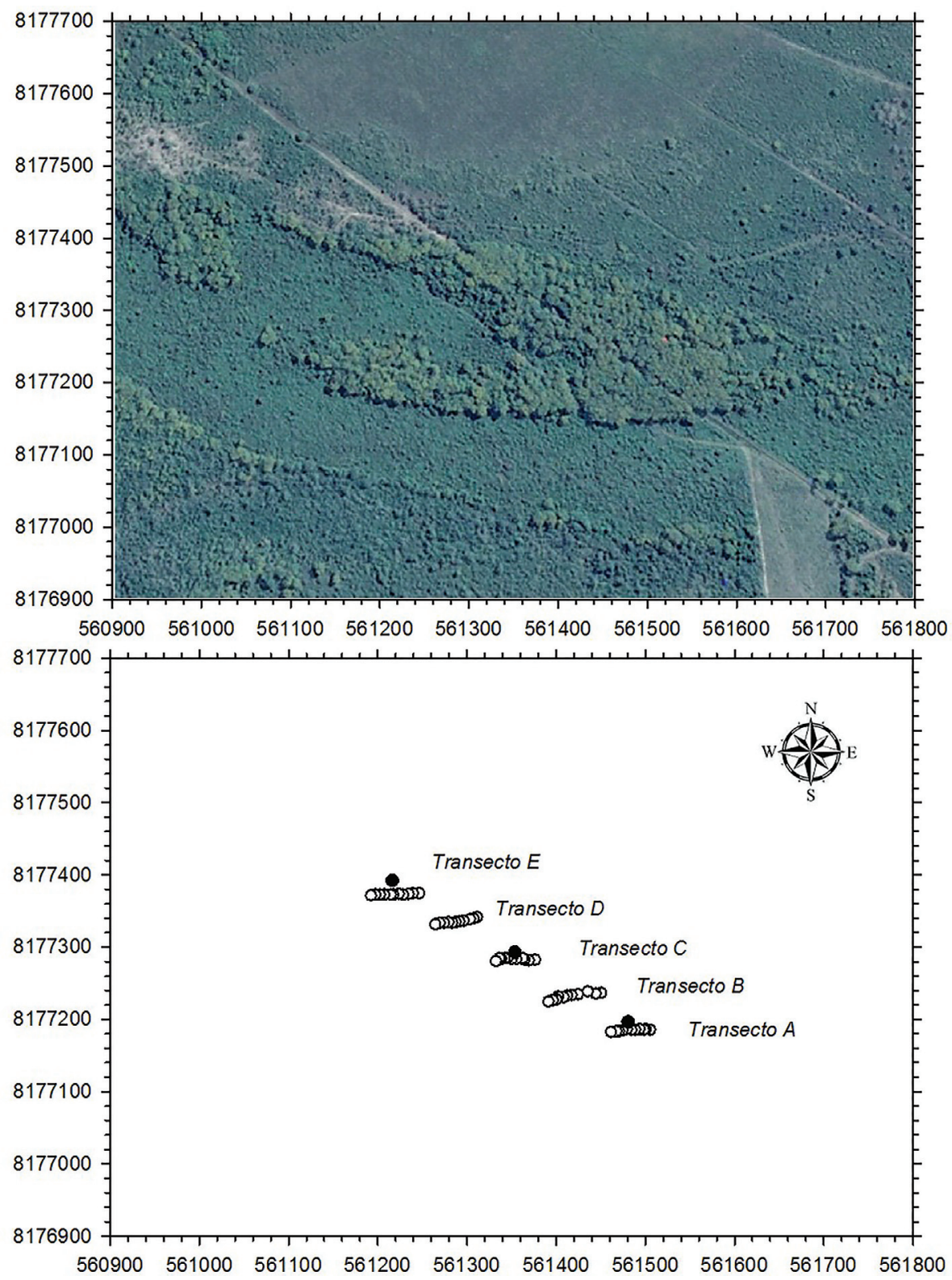

Figura 1 - Área de estudo e localização dos pontos de medições (círculos abertos) nos transectos A, B, C, D e E, e localização das estações meteorológicas instaladas abaixo do dossel (círculos fechados) em área inundável de Vochysia divergens Pohl em 2012. Cada transecto possui 11 pontos de amostragem. Unidade em Universal Transversa de Mercator - UTM. 
a aproximadamente $2 \mathrm{~km}$ da área em estudo em que foi medido o albedo do solo.

Três estações meteorológicas (WatchDog 2000, Spectrum Tecnologies, USA) foram fixadas nos transectos A, C e E, uma em cada um dos transectos (instaladas no centro do transecto), para medição da radiação solar global incidente que atravessa o dossel $\left(\mathrm{Rg}_{\text {inc }}\right)$ e radiação global refletida pelo solo $\left(\mathrm{Rg}_{\mathrm{ref}}\right)$. A $2 \mathrm{~m}$ do solo, para a medição da $\mathrm{Rg}_{\text {inc }}$ e $\mathrm{Rg}_{\text {ref }}$ foram instalados dois piranômetros no topo da torre um com a face voltada para cima, e o outro com a face voltada para baixo, respectivamente. Os dados foram coletados e armazenados a cada 30 min durante 2012.

A umidade do solo foi medida por um refletômetro no domínio do tempo (Time Domain Reflectometry, TDR, Hidrosense TM, Campbell Scientific, Austrália), medida mensalmente em 55 pontos em uma profundidade de 0-10 $\mathrm{cm}$, de julho a novembro de 2012.

\subsection{Determinação da altura da lâmina d'água sobre o solo}

A altura da lâmina d'água $(\mathrm{L}, \mathrm{cm})$ foi medida mensalmente por meio de uma régua graduada nos 55 pontos, 11 pontos por transecto, durante o período de inundação (fevereiro a junho e dezembro de 2012).

\subsection{Determinação da serrapilheira acumulada sobre o solo}

A serrapilheira acumulada sobre o solo foi coletada mensalmente por meio de um molde vazado $(25 \times 25 \mathrm{~cm})$ colocado sobre o solo no qual todo material vegetal contido dentro do molde foi retirado como amostra em 20 pontos (Haase, 1999). Cada transecto possuía 4 pontos de coleta. No laboratório as amostras de produção de serrapilheira e serrapilheira acumulada sobre o solo foram transferidas para sacos de papel kraft identificados e colocados em estufa de circulação forçada (Orion 520, FANEM, São Paulo, Brasil) a uma temperatura de $70{ }^{\circ} \mathrm{C}$ durante $72 \mathrm{~h}$ ou até apresentarem peso constante. Posteriormente foram pesadas separadamente em balança analítica (AD 500, Marte, Santa Rita do Sapucaí, Brasil).

\subsection{Estimativa do albedo do solo}

$\mathrm{O}$ albedo do solo $\left(\alpha_{\text {solo }}\right)$ foi estimado pela razão entre a radiação global refletida pelo solo abaixo do dossel $\left(\operatorname{Rg}_{\text {ref }}\right)$ e a radiação global incidente abaixo do dossel $\left(\mathrm{Rg}_{\text {in }}\right)$ com dados das variáveis meteorológicas instaladas nos transectos A, C e E (Foken, 2008).

No intuito de verificar as relações entre as variáveis foi utilizado o teste de Kolmogorov-Smirnov como decisão para uso da estatística não-paramétrica (Callegari-Jacques e Sídia, 2003). Em seguida, foi utilizada a correlação de Spearman $(\rho)$ para verificar o grau de correlação entre o albedo do solo e outras variáveis (Spearman, 1904).

\section{.3. Resultados e Discussão}

\subsection{Descrição do padrão hidrológico anual}

A precipitação acumulada mensal e a média mensal da umidade do solo apresentaram sazonalidade no decorrer de 2012, com menores valores durante os meses de seca e maiores no nos meses úmidos (Fig. 2). Do total, $48 \%$ da precipitação pluviométrica acumulada na região ocorreram na estação úmida, período em que ocorre a inundação, e apenas $1 \%$ ocorreu na estação seca. A precipitação acumulada máxima mensal, $421 \mathrm{~mm} / \mathrm{mês}$, ocorreu em novembro, contrastando com julho e agosto, em que não houve precipitação.

$\mathrm{O}$ padrão de precipitação pluviométrica na área de estudo está de acordo com estudos realizados na região do Pantanal Mato-Grossense por Sanches et al. (2011) que encontraram $1414 \mathrm{~mm}$ de precipitação acumulada em 2007, ocorrendo em novembro e dezembro as maiores precipitações, representando $50 \%$ do total anual. Ainda de acordo com Fantim-Cruz et al. (2010) que verificaram que $80 \%$ da precipitação ocorreu entre novembro e março em 2006/2007. Ainda de acordo com a média de série histórica de dados pluviométricos de $1420 \mathrm{~mm}$ (Machado et al., 2004).

A umidade do solo acompanhou a sazonalidade da precipitação atingindo o valor mínimo mensal de 3,81\% em setembro. Durante janeiro a julho e em dezembro a umidade do solo foi superior a $45 \%$, e neste caso considerou-se que o solo se encontra em saturação.

A altura da lâmina d'água sobre o solo apresentou sazonalidade similar à precipitação ocorrendo durante janeiro a junho com maiores valores durante março e abril, dependendo do ponto de medição. A Fig. 2 apresenta a média da lâmina d'água nos 55 pontos de medições e, por tanto, pode ser considerada como uma referência do padrão hidrológico de inundação. As médias mensais das alturas de lâmina d'água (L) sobre o solo em todos os transectos ocorreram de fevereiro $(0,48 \mathrm{~cm})$ a junho $(0,29)$ com maior valor de L (7,54 cm) em março (Fig. 2) coincidindo com a precipitação pluviométrica no local (Fig. 2). A inundação nesta área se deve principalmente a baixa capacidade de percolação de água no solo devido às características do solo e a topografia relativamente plana da área. As maiores $\mathrm{L}$ ocorreram no transecto $\mathrm{E}(6,2 \mathrm{~cm})$ e menores no transecto $\mathrm{A}$ $(1,4 \mathrm{~cm})$, provavelmente devido à variação da cota topográfica.

\subsection{Variação mensal da radiação solar global incidente e refletida}

A radiação solar global $(\mathrm{Rg})$ apresentou sazonalidade característica com menores médias mensais nos meses secos (Fig. 3). As maiores médias mensais de $\mathrm{Rg}_{\text {inc }}$ foram $24,97 \mathrm{~W} \mathrm{~m}^{-2}$ e $23,69 \mathrm{~W} \mathrm{~m}^{-2}$ no transecto A e C, respec- 


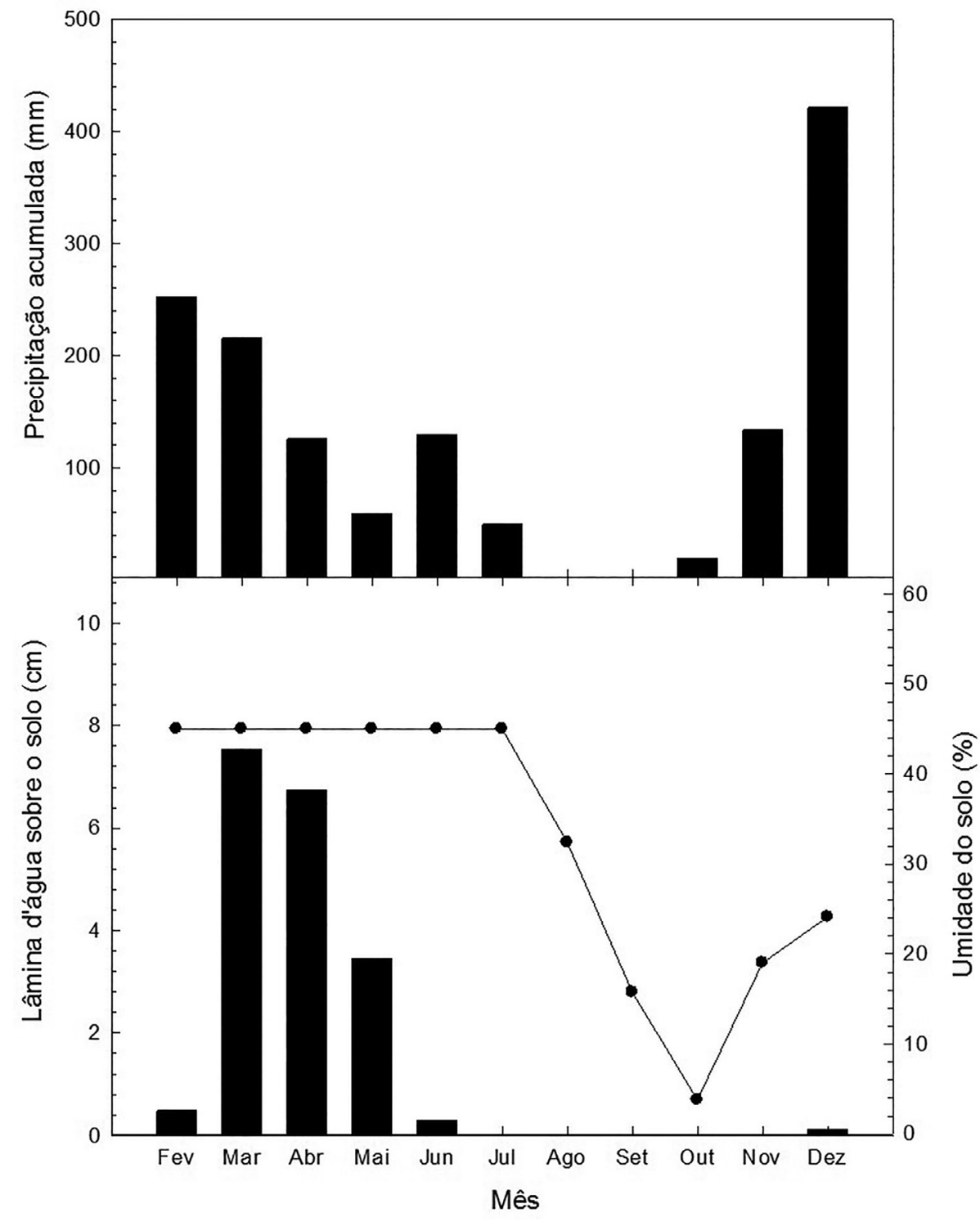

Figura 2 - Precipitação acumulada mensal (mm), média da umidade do solo (\%) e da lâmina d'água sobre o solo ( $\mathrm{cm}, n=55$ pontos) em área inundável de Vochysia divergens Pohl em 2012.

tivamente, em setembro. No transecto E, a maior média de $\mathrm{Rg}_{\text {inc }}$ foi $54,3 \mathrm{~W} \mathrm{~m}^{-2}$ em dezembro de 2012 (Fig. 3).

As menores médias diárias da $\operatorname{Rg}_{\text {ref }}$ ocorreram março (período de inundação) nos transectos $\mathrm{A}, \mathrm{C}$ e E, respectivamente (Fig. 3). Provavelmente devido a saturação de água no solo e consequentemente a coloração escura da água, devido ao alto teor de matéria orgânica no solo, presente na área de estudo (Johnson et al., 2013). As maiores médias ocorreram em setembro nos transectos $\mathrm{A}, \mathrm{C} \mathrm{e} \mathrm{E}$, respectivamente, provavelmente porque o solo está mais seco neste final do período de estiagem.

\subsection{Variação diária do albedo do solo}

As maiores médias diárias do albedo do solo $\left(\alpha_{\text {solo }}\right)$ ocorreram durante os meses secos e as menores durante os meses úmidos, em média variando de $0 \%$ atingindo $47 \%$ (Fig. 4). Os maiores valores ocorreram no transecto C, provavelmente porque neste transecto havia maior quantidade de clareiras que favorecem a penetração da radiação solar global e consequentemente uma maior diminuição da umidade do solo. Apesar do transecto E apresentar vegetação menos densa com menor quantidade de $V$. divergens, o mesmo não apresenta clareiras como no transecto $C$. Os valores de refletância do solo em superfícies alagadas estão de acordo com Silva et al. (2005), que encontraram valores menores que $10 \%$ para superfícies d'agua, como lagos e açudes.

Em média houve o aumento de 50,85\%, 42,85\% e $32,35 \%$ do albedo do período de inundação e de seca, respectivamente nos transectos $\mathrm{A}, \mathrm{C}$ e $\mathrm{E}$. A variação no 


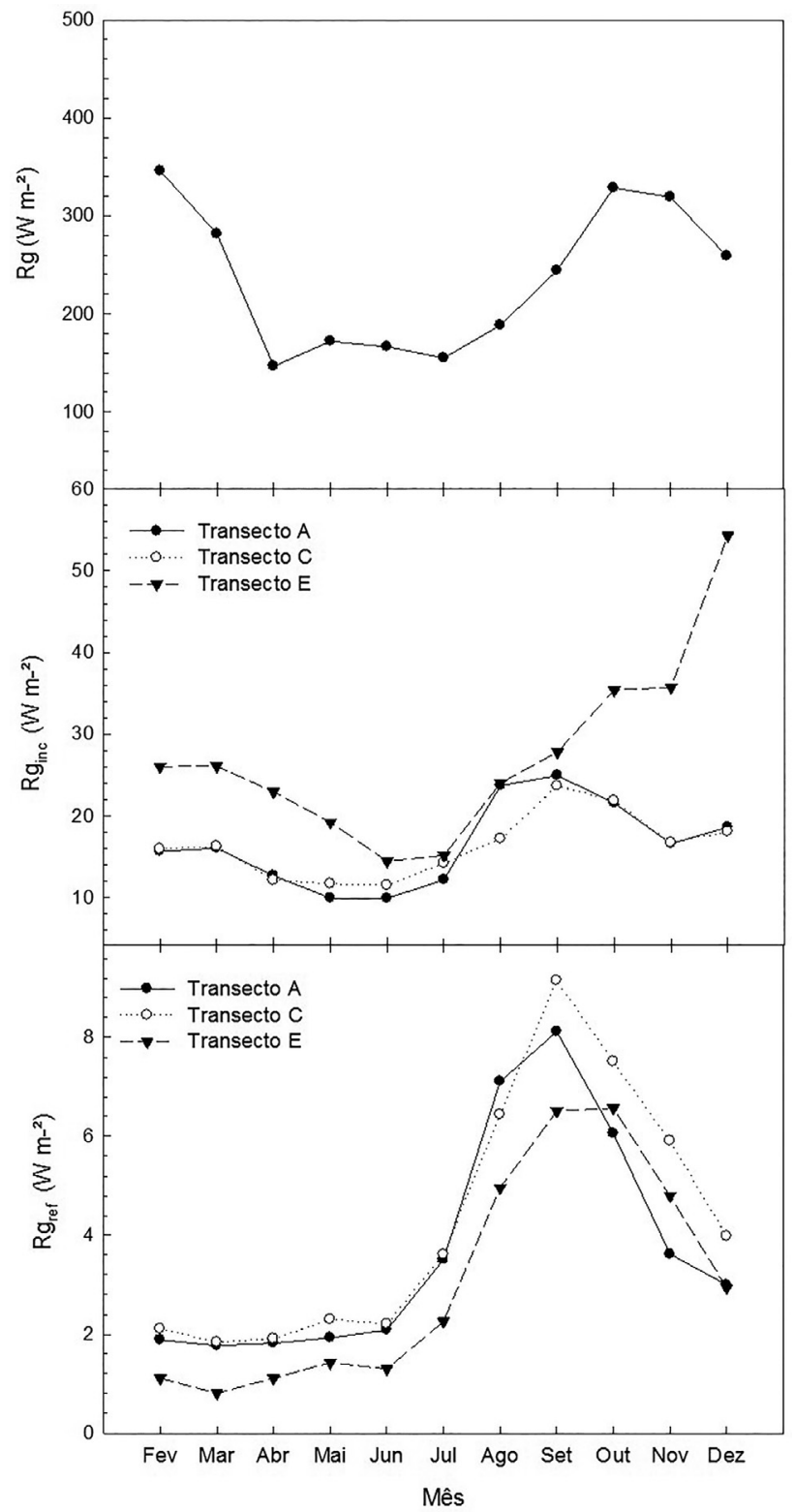

Figura 3 - Média mensal da radiação solar global incidente fora do dossel da floresta $\left(\mathrm{Rg}, \mathrm{W} \mathrm{m}^{-2}\right)$ em 2013; média mensal da radiação solar incidente abaixo do dossel $\left(\mathrm{Rg}_{\text {inc }}, \mathrm{W} \mathrm{m}^{-2}\right)$ e da refletida abaixo do dossel $\left(\mathrm{Rg}_{\text {ref, }}\right.$ $\mathrm{Wm}^{-2}$ ) em área inundável de Vochysia divergens Pohl em 2012. Os dados da Rg são apresentados somente como referencia da radiação solar global na região.

aumento do albedo está associada à duração da inundação em cada transecto, sendo que o transecto $\mathrm{E}$ teve maior duração de inundação. Houve diferença significativa entre as médias diárias do albedo do solo nos transectos $\mathrm{C}$ e $\mathrm{E}$ ( $\mathrm{H}=12,71, \mathrm{GL}=2$, p-valor $<0,001)$, com maiores médias no transecto $\mathrm{C}$ e menores no transecto $\mathrm{E}$. O albedo do solo nos transectos apresentou forte correlação positiva entre si, indicando que eles apresentaram a mesma variação mensal.

O albedo diário do solo variou de 0 a $15 \%$ nos meses de inundação e de 10 a 25\% no final da estação seca. Os maiores valores no final da estação seca ocorreram no

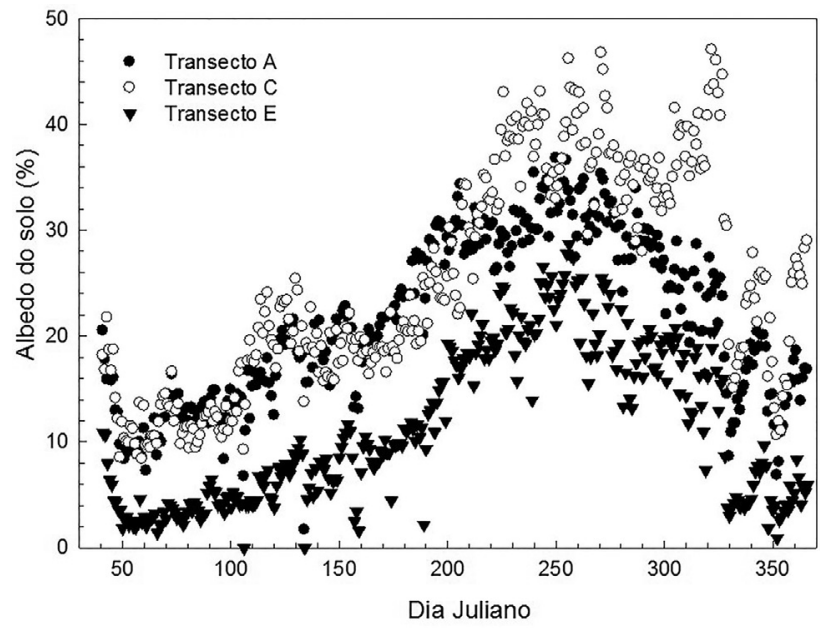

Figura 4 - Média diária do albedo do solo $\left(\alpha_{\text {solo }}, \%\right)$ nos transectos $\mathrm{A}, \mathrm{C}$ e E em área inundável de Vochysia divergens Pohl em 2012.

transecto $\mathrm{C}$ e os menores no $\mathrm{E}$. A maior variabilidade do albedo ocorreu em outubro (início da estação chuvosa) com valores entre 5 e $25 \%$. O mês de outubro representa um período de transição entre as estações seca e chuvosa. Portanto, intervalos alternados de dias com e sem chuva podem ocorrer, o que afeta a umidade do solo, e consequentemente o albedo do solo, provocando maior variação do albedo.

Estudos sobre a variação diária do albedo em superfície com solo úmido indicaram que o albedo do solo pode variar substancialmente em curto prazo, uma vez que um solo saturado de água pode apresentar a metade do valor do albedo em relação ao solo seco (Liu et al., 2014).

A variação do albedo do solo no período de inundação e seco pode ser influenciada por vários fatores. $\mathrm{O}$ próprio dossel da vegetação atenuou a entrada da radiação global solar e, por esse motivo no período de inundação à absorção de energia térmica pela água não foi relativamente superior à atmosfera. Além disso, a maior quantidade de vapor de água no ar durante a estação chuvosa contribuiu no aumento da capacidade térmica do ar (Novais et al., 2012).

Em alguns estudos realizados em áreas alagadas foi considerado que as mudanças no armazenamento de calor da água foram maiores que as mudanças no armazenamento de energia na biomassa e no ar dentro do dossel (Bidlake et al., 1996; German, 2000). Isso porque a capacidade térmica da água é quase o dobro da capacidade térmica da vegetação, solo e matéria orgânica.

A variação do albedo também esteve suscetível a variação das pequenas clareiras, decorrentes da diferença da estrutura da vegetação (por exemplo, composição e densidade populacional) e dinâmica da vegetação (por exemplo, perda de folhas e queda de galhos), consequentemente variação no índice de área foliar, influenciando sobre o sensor que pode estar exposto a radiação direta 
incidente e/ou difusa. Além disso, a variação do albedo pode estar relacionada a nebulosidade, geometria da copa, direção prevalente do vento, velocidade do vento e ângulo zenital (Querino et al., 2006; Vilani et al., 2007), principalmente quando associadas a menor escala temporal como variação horária.

Outro fator é que o albedo do solo varia amplamente, dependendo em grande parte da composição mineralógica e umidade do solo (Zhou et al., 2003), entretanto isso também depende em que escala temporal se realiza uma analisa de dados, ou seja, em geral as características do solo na área em estudo podem ser consideradas similares, o solo possui semelhantes características em termos de variação espacial. Assim, considera-se que o albedo do solo também é influenciado pela textura do mesmo, pois a composição de seixos, pedras e proporção relativa de areia e argila irão moldar a dependência da umidade sobre o albedo do solo (Liu et al., 2014), principalmente em escalas de tempo curtas. Nesse sentido, considerou-se que a variação do albedo nos transectos não esteve relacionada diretamente a textura e sim ao grau de porosidade; devido às mudanças de cor aparente do solo em função da umidade do solo.

\subsection{Variação do albedo do solo em função da precipitação, umidade do solo e da serrapilheira acumulada sobre o solo}

Com o declínio da precipitação e consequentemente diminuição da lâmina d'água, houve um aumento do albedo do solo nos transectos (Figs. 2, 3 e 5), entretanto a precipitação acumulada mensal e o albedo do solo não foram correlacionados no mês atual, estas variáveis apresentaram correlações negativas nos próximos 3 meses e correlações positivas após 7-9 meses (Fig. 6). Isso significa que o albedo do solo esteve sendo influenciado pela precipitação mensal ocorrida em meses anteriores.

A maior média mensal de serrapilheira acumulada sobre o solo ocorreu durante setembro a dezembro (Fig. 5). Até junho, o solo estava inundado e/ou saturado, a partir de julho, a medida que o solo secava e a umidade do ar diminuía, e o acúmulo de serrapilheira sobre o solo foi ocorrendo gradualmente (Silva, 2013). A partir de setembro houve acentuada senescência foliar, que cobria o solo com uma grossa camada de folhas secas com coloração mais clara que o próprio solo nu e o solo encharcado/saturado, influenciando na refletância da superfície com o seu aumento.

A umidade do solo nos transectos e o albedo do solo apresentaram correlações negativamente significantes nos meses atuais (Fig. 6, mês de defasagem 0 mês), indicando que com o aumento da umidade do solo houve uma diminuição do albedo do solo (conforme Figs. 2 e 3). Durante os meses de seca houve correlações positivamente significantes entre a umidade e o albedo do solo nos três transectos (Fig. 6).

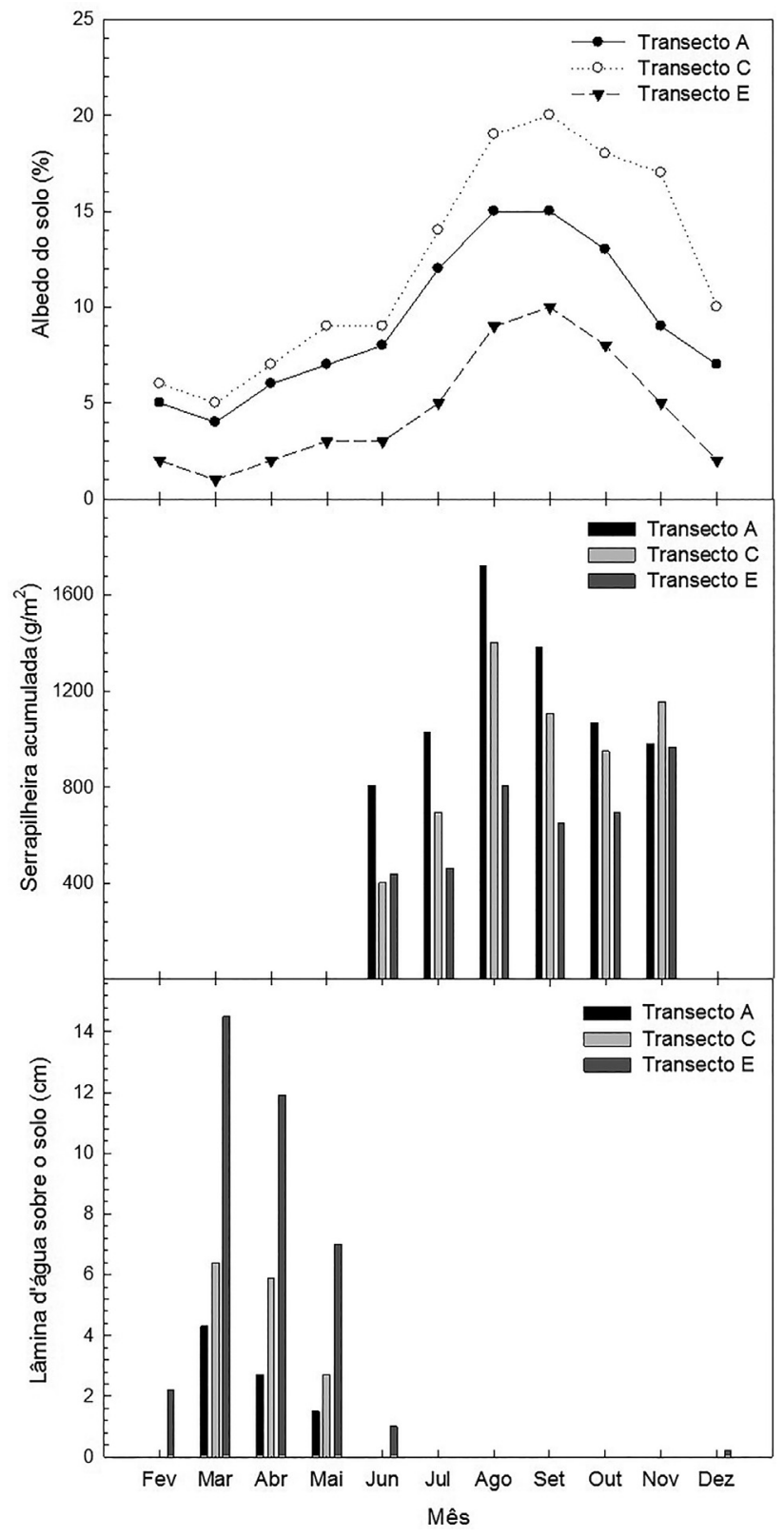

Figura 5 - Média mensal do albedo do solo $(\%, n=11)$, da serrapilheira acumulada sobre o solo $\left(\mathrm{g} / \mathrm{m}^{2}, n=4\right)$, lâmina d'água sobre o solo $(\mathrm{cm}$, $n=11)$ nos transectos A, C e E em área inundável de Vochysia divergens Pohl em 2012.

Outra questão que deve ser abordada é que a decomposição das folhas apresenta variação de todos os pigmentos. A estrutura interna da folha, quando em decomposição, entra em colapso, principalmente a celulose, passando por diferentes estágios, da cor de amarela ao marrom, cinza ao preto (Van Leeuwen e Huete, 1996). Por outro lado, a variação da umidade do solo influencia diretamente a fisiologia vegetal, em que estudos (Silva et al., 2005; Sanches et al., 2008) tem demonstrado que a sazonalidade na produção de serrapilheira, pode ser atribuído a característica de espécies vegetais de áreas tropicais que perdem suas folhas 

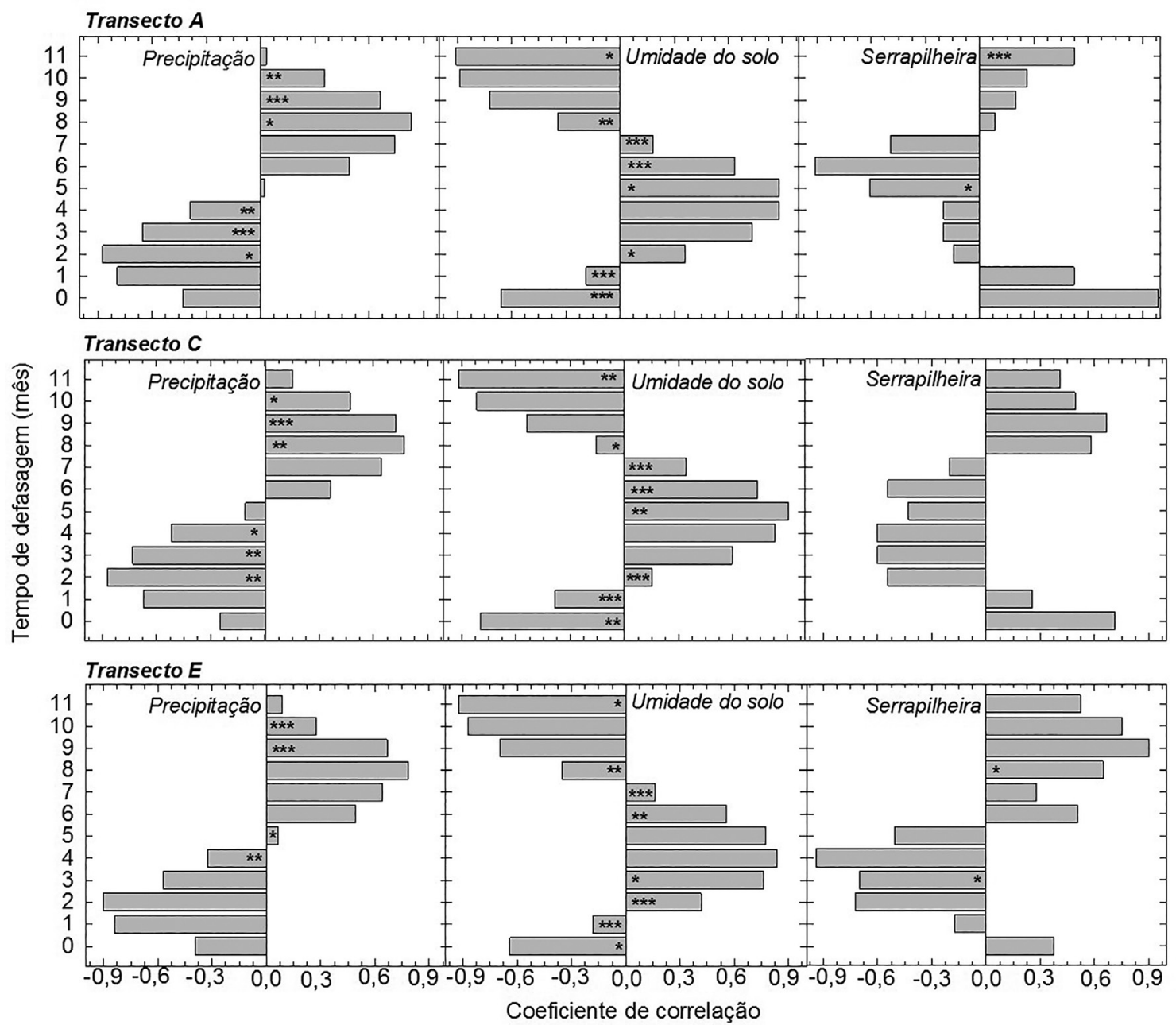

Figura 6 - Coeficiente de correlação de Spearman entre a precipitação acumulada mensal, a média mensal da umidade do solo e a serrapilheira acumulada sobre o solo como uma função da média mensal do albedo do solo $\left(\alpha_{\text {solo }}\right)$. Para estas análises, as séries temporais do albedo do solo foram defasadas em relação as demais variáveis de 1 a 11 meses. $(\mathrm{p}<0,05) ;(\mathrm{p}<0,01) ;(\mathrm{p}<0,001)$.

na época seca de modo a perder menos água nas trocas gasosas. O padrão sazonal de serrapilheira acumulada sobre o solo foi positivamente correlacionado com o albedo nos transectos $\mathrm{A}$ e $\mathrm{C}$, enquanto que no transecto $\mathrm{E}$ não foi observada correlação, (Fig. 6, tempo de defasagem 0 mês). Enquanto que o albedo do solo nos três transectos foram negativamente correlacionados com a serrapilheira nos 6 meses de transição dos meses seco para o início da inundação (Fig. 6).

\section{Conclusão}

Ao analisar o albedo do solo $\left(\alpha_{\text {solo }}\right)$ em área inundável de Vochysia divergens Pohl em 2012, constatou-se que o mesmo variou sazonalmente com menores valores durante os meses seco, diminuindo em 50,85\%, 42,85\% e 32,35\% durante o período de inundação nos transectos A, C e E. As variações anuais no a $\alpha_{\text {solo }}$ concordam com a dinâmica da camada sobre o solo que no período de inundação é coberto por lâmina d'água e no período seco, o solo esteve coberto pela serrapilheira acumulada sobre o solo. Considerando a sazonalidade, a correlação cruzada entre $\alpha_{\text {solo nos }}$ transectos A, C e E e as variáveis hidrológicas (precipitação e umidade do solo) e entre o $\alpha_{\text {solo }}$ nos transectos A, C e E e a serrapilheira acumulada sobre o solo houve variação, mas pode explicar em parte a influencia direta e/ou indireta das mesmas. A precipitação acumulada mensal não influenciou diretamente sobre o albedo do solo do mês atual, enquanto que a umidade do solo se correlacionou positivamente com o $\alpha_{\text {solo }}$ no mês atual indicando influencia direta.

\section{Agradecimentos}

Essa pesquisa foi desenvolvida com suporte financeiro do Conselho Nacional de Desenvolvimento Científico e Tecnológico - CNPq (Processo 47880/2010-6), e da Fundação de Amparo à Pesquisa de Mato Grosso FAPEMAT (Processo 286742/2010), com suporte adicional da Coordenação de Aperfeiçoamento de Pessoal de Nível Superior - CAPES, e com suporte logístico da Uni- 
versidade Federal de Mato Grosso - UFMT e da Estância Ecológica SESC Pantanal.

\section{Referências}

AMARAL FILHO, Z.P. Solos do Pantanal Mato-Grossense. In Anais do $\mathbf{1}^{\circ}$ Simpósio sobre recursos naturais e socioeconômicos do Pantanal. EMBRAPA-CPAP-UFMS, 265 p. (EMBRAPA-CPAP, Documentos, 5). 1984.

BIDLAKE, W.R.; WOODHAM, W.M.; LOPEZ, M.A. Evapotranspiration from areas of native vegetation in west-central Florida. 1.ed. New York, US Geological Survey WSP 2430, 1996, 35p.

BRUTSAERT, W. Evaporation into the atmosphere-theory, history, and applications. 1.ed. Boston, Springer, Kluwer Academic Publishers, 1982, 302p.

CALLEGARI-JACQUES, S.M. Bioestatística: princípios e aplicações. 264 p., Artmed, 2003.

DA SILVA, C. J. Ecological basis for the management of the Pantanal-Upper Paraguay River basin. In SMITS, A.J.M.; NIENHUIS, P.H.; LEUVEN R.S.E.W. (eds), New Approaches to River Management. Leiden, Bachuys Publishers, 2000, pp. 97-117.

DA SILVA, C.J.; GIRARD P. New challenges in the management of the Brazilian Pantanal and catchment area. Wetlands Ecology and Management, v. 12(6), 553-561, 2004. doi:10.1007/s11273-005-1755-0.

FANTIN-CRUZ, I.; LOVERDE-OLIVEIRA, S.; GIRARD, P. Caracterização morfométrica e suas implicações na limnologia de lagoas do Pantanal Norte. Acta Scientiarum Biological Sciences, v. 30(2), p. 133-140, 2008.

FANTIN-CRUZ, I.; GIRARD, P.; ZEILHOFER, P.; COLLISCHONN, W.; NUNES DA CUNHA, C. Unidades fitofisionômicas em mesoescala no Pantanal Norte e suas relações com a geomorfologia. Biota Neotropica, v. 10(2), p. 31-38, 2010.

FOKEN, T. Translated by NAPPO, C.J. Micrometeorology, 1 ed., 308 p., Springer, Germany, 2008.

GERMAN, E.R. Regional evaluation of evapotranspiration in the Everglades. 1.ed. New York, U.S. Geological Survey Water Resources Investigations Report 00-4217, 2000, 14 p.

GONÇALVES, H.C.; MERCANTE, M.A.; SANTOS, E.T. Hydrological cycle. Brazilian Journal of Biology, v. 71(1), p. 241-253, 2011. http://dx.doi.org/10.1590/S151969842011000200003.

HAASE, R. Litterfall and nutrient return in seasonally flooded and nonflooded forest of the Pantanal, Mato Grosso, Brazil. Forest Ecological Management, v. 117(1-3), p. 29-147, 1999.

IRIONDO, M. Large wetlands of South America: a model for quaternary humid environments. Quaternary International, v. 114(1), p. 3-9, 2004. doi:10.1016/S10406182(03)00037-5.

JOHNSON, M.S.; COUTO, E.G.; PINTO, O.B. JR.; MILESI, J.; SANTOS AMORIM, R.S.; MESIAS, I.A.M.; BIUDES, M.S. Soil $\mathrm{CO}_{2}$ Dynamics in a Tree Island Soil of the Pantanal: The Role of Soil Water Potential. PLoS ONE, v. 8, n. 6, e64874. doi:10.1371/journal.pone.0064874, 2013.

JUNK, W.J.; NUNES DA CUNHA, K.; WANTZEN, C.K.M.; PETERMANN, P.; STRÜSSMANN, C.; MARQUES, M.I.; ADIS, J. Biodiversity and its conservation in the Pantanal of
Mato Grosso, Brazil. Aquatic Sciences, v. 68, p. 278-309, 2006. doi:10.1007/s00027-006-0851-4.

LIU, S.; ROUJEAN, J.L.; TCHUENTE, A.T.K.; CEAMANOS, X.; CALVET, J.C. A parameterization of SEVIRI and MODIS daily surface albedo with soil moisture: Calibration and validation over southwestern France. Remote Sensing of Environment, v. 144, p. 137-151, 2014. doi:10.1016/j.rse.2014.01.016.

LOISELlE, S.; BRACCHINI, L.; BONECHI, C.; ROSSI, C. Modelling energy fluxes in remote wetland ecosystems with the help of remote sensing. Ecological Modelling, 145(2-3), p. 243-261, 2001 http://dx.doi.org/10.1016/S03043800(01)00394-5.

LUCHT, W.; HYMAN, A.H.; STRAHLER, A.H., BARNSLEY, M.J.; HOBSON, P.; MULLER, J.P. A comparison of satellite-derived spectral albedos to ground-based broadband albedo measurements modeled to satellite spatial scale for a semidesert landscape. Remote Sensing of Environment, v. 74(1), p. 85-98, 2000. doi: 10.1016/S0034-4257(00)001255.

MACHADO, L.A.T.; LAURENT, H.; DESSAY, N.; MIRANDA I. Seasonal and diurnal variability of convection over the Amazonia: a comparison of different vegetation types and large scale forcing. Theoretical and Applied Climatology, v. 78, n. 1-3, p. 61-77, 2004. doi:10.1007/s00704-0040044-9.

NOVAIS, J.W.Z.; RODRIGUES, T.R.; CURADO, L.F.A.; OLIVEIRA, A.G.; DE PAULO, S.R.; NOGUEIRA, J.S. Variabilidade Sazonal Horária das Propriedades Térmicas em Gleissolo Háplico no Norte do Pantanal. Semina. Ciências Agrárias, v. 33, p. 2563-2570, 2012.

NOVAIS, J.W.Z.; RODRIGUES, T.R.; CURADO, L.F.A.; OLIVEIRA, A.G.; DE PAULO, S. R.; NOGUEIRA, J.S.; OLIVEIRA, R.G. Geothermal Dynamics in Vochysia divergens Forest in a Brazilian Wetland. Air, Soil and Water Research, v. 6, p. 47-52, 2013. doi:10.4137/ASWR.S11364.

NUNES DA CUNHA, C.; JUNK, W.J. Distribution of wood plant communities along the flood gradient in the Pantanal of Poconé, Mato Grosso, Brazil. International Journal of Ecology and Environmental, v. 27(2), p. 63-70, 2001.

QUERINO, C.A.S.; MOURA, M.A.L.; LYRA, R.F.F.; MARIANO, G.L. Avaliação e comparação de radiação solar global e albedo com ângulo zênital na região Amazônica. Revista Brasileira de Meteorologia, v. 21(3a), p. 42-49, Junho-Julho, 2006.

SANCHES, L.; SULI, G.S.; PRIANTE FILHO, N.; VOURLITIS, G.L.; NOGUEIRA, J.S. Índice de área foliar em floresta de transição Amazônia Cerrado. Ciência e Natura, v. 1, p. 37-46, 2008.

SANCHES, L.; VOURLITIS, G.L.; ALVES, M.C.; PINTO-JUNIOR, O.B.; NOGUEIRA, J.S. Seasonal patterns of evapotranspiration for a Vochysia divergens forest in the Brazilian Pantanal. Wetlands, v. 31, p. 1215-1225, 2011.

SCHWERDTFEGER, J.; JOHNSON, M.S.; COUTO, E.G.; AMORIM, R.S.S.; SANCHES, L.; CAMPELO JÚNIOR, J.H.; WEILER, M. Inundation and groundwater dynamics for quantification of evaporative water loss in tropical wetlands. Hydrology and Earth System Sciences, v. 11, p. 4017-4062, 2014. doi:10.5194/hessd-11-4017-2014.

SILVA, B.B. DA; LOPES, G.M.; AZEVEDO, P.V. Determinação do albedo de áreas irrigadas com base em imagens 
Landsat 5 - TM. Revista Brasileira de Agrometeorologia, v. 13(2), p. 201-211, 2005.

SILVA, L.B. Relações entre aporte de serrapilheira, nutrientes e efluxo de dióxido de carbono em floresta inundável de Vochysia divergens Pohl no Pantanal Mato-Grossense. Tese de doutorado do Programa de Pós-Graduação em Física Ambiental, Universidade Federal de Mato Grosso, 2013.

SPEARMAN, C. The proof and measurement of association between two things. American Journal Psychology, v. 15, p. 72-101, 1904.

SUMNER, D.M.; WU, Q.; PATHAK C.S. Variability of albedo and utility of the MODIS albedo product in forested wetlands. Wetlands, v. 31, p. 229-237, 2011.

TWINE, T.E.; KUCHARIK, C.J.; FOLEY, J.A. Effects of land cover change on the energy and water balance of the Mississippi River Basin. Journal of Hydrometeorology, v. 5, p. 640-655, 2004.

VAN LEEUWEN, W.J.D.; HUETE, A.R. Effects of standing litter on the biophysical interpretation of plant canopies with spectral indices. Remote Sensing Environment, v. 55, n. 2, p. 123-138, 1996. doi:10.1016/0034-4257(95)00198-0.

VILANI, Maricéia Tatiana2007VILANI, M.T.; SANCHES, L.; COSTA, M.H.; GAIO, D.C.; NOGUEIRA, J.S. Estimativa da fapar utilizando três métodos para uma floresta de transição Amazônia Cerrado. Revista Brasileira de Agrometeorologia, v. 15, p. 289-298, Dezembro, 2007.
VICTORIA, R.L.; FERNANDES, F.; MARTINELLI, L.A.; PICCOLO, M.C.; CAMARGO, P.B.; TRUMBORE, S. Past vegetation changes in the Brazilian Pantanal arboreal-grassy savanna ecotone by using carbon isotopes in the soil organic matter. Global Change Biology, v. 1, p. 165-171, 1995. doi: 10.1111/j.1365-2486.1995.tb00018.x.

WANG, W.; CHEN, J. New calculation methods of diurnal distributions of solar radiation and its interception by canopy over complex terrain. Ecological Modelling, v. 155, n. 2-3, p. 191-204, 2002. doi:10.1016/S0304-3800(02)00122-9.

ZEILHOFER, P.; SCHESSL, M. Relationship between vegetation and environmental conditions in the northern Pantanal of Mato Grosso, Brazil. Journal of Biogeography, v. 27(1), p. 159-168, 2001. doi: 10.1046/j.1365-2699.2000.00357.x.

ZEILHOFER, P.; MOURA, R.M. Hydrological changes in the Northern Pantanal caused by the Manso dam: Impact analysis and suggestions for mitigation. Ecological Engineering, v. 35, p. 105-117, 2009. doi: 0.1016/j.ecoleng.2008.09.011

ZHOU, L.; DICKINSON, R.E.; TIAN, Y.; ZENG, X.; DAI, Y.; YANG, Z.-L.; SCHAAF, C.B.; GAO, F.; JIN, Y.; STRAHLER, A.; MYNENI, R.B.; YU, H.; WU, W.; SHAIKH, M. Comparison of seasonal and spatial variations of albedos from Moderate-Resolution Imaging Spectroradiometer (MODIS) and common land model. Journal of Geophysical Research, 108(D15), p. 4488. doi:10.1029/2002JD003326, 2003.

All the contents of this journal, except where otherwise noted, is licensed under a Creative Commons Attribution License CC-BY. 